\title{
Performance Assessment of a High-Powered Boost Converter for Photovoltaic Residential Implementations
}

\author{
Davood Ghaderi*, Gokay Bayrak \\ Department of Electrical and Electronics Engineering, Bursa Technical University, \\ Bursa, Turkey \\ davood.ghaderi@btu.edu.tr,gokay.bayrak@btu.edu.tr
}

\begin{abstract}
This paper introduces a new boost converter operating in several duty cycles with a high powered and no transformer design for Photovoltaic residential implementations. The proposed converter is performed without any extra power switch by a voltage pre-amplifier unit between the input inductor and the power switch and is derived with a simple structure. The designed converter provides a voltage gain by 38 times for the operation of $90 \%$ of the duty cycle. This condition shows that the proposed converter has more efficient compared to the conventional boost converters. Besides, a higher amount of DC gain is possible by adding a cascade blocks connection of switched-capacitor (SC) in the converter's output. The operational principles are evaluated to justify the utility of converter for residential PV systems in the study. Also, a $200 \mathrm{~W}$ powered prototype converter is implemented by applying a commercial PV panel in the laboratory. The experimental results confirm both the mathematical and simulation results.
\end{abstract}

Index Terms-Residential PV-system; Single switched power boost converter; Switched capacitor (SC) structure.

\section{INTRODUCTION}

The microgrids consist of solar, wind, and other renewable energy sources (RES), and the photovoltaic (PV)based residential power plants are widely used in RESconnected grid applications. There are over two million residential PV power plants only in Germany, and most of these plants have installed in power ranges less than $5 \mathrm{kWp}$ [1]. A boost converter circuit is required in a PV-based power generation system because of variable weather conditions [2], [3], and it is generally used to provide a continuous DC voltage to the input of a grid-connected inverter, and also to the DC loads [4], [5].

The conventional high-powered boost converters consist of a transformer and a coupled inductor to obtain a high voltage gain in PV systems [6], [7]. Besides, the energy loses in the leakage inductor is a significant problem for boost converters having a coupled inductor. This condition causes high voltage stresses, and also the considerable switching power loses in the boost converters. different structures have been suggested to ravel out these troubles

Manuscript received 15 January, 2019; accepted 2 April, 2019.

This research was funded by a grant (No. 182N12) from the Scientific Research Projects Units of Bursa Technical University, Bursa, Turkey.
[8]-[11].

In the literature, the similar boost converters are connected in parallel in interleaved boost structures to overcome these issues.

In spite of increasing the efficiency and voltage and current gains of the boost converters with interleaved topologies, using more components in converter design increases the total cost of the circuit.

This study presents a modified switched capacitor boost converter. The main advantages of the study to the literature can be listed, respectively:

- Design and implementation of a new boost converter consisting of a high voltage gain and no transformer;

- The designed converter provides a voltage gain by 38 times for the operation of $90 \%$ of the duty cycle;

- A useful design structure is providing high DC gain by connecting the switched capacitor units in the output of the circuit.

The designed PV-based system is applied in real-time conditions to assess the compatibility of the proposed system with the grid.

\section{RESIDENTIAL PV-BASEd Power Plant SysteM STUdIED}

In this section, the studied PV system is introduced. Figure 1 shows the PV-based residential power generation plant and the proposed boost converter in this system.

We can design two different controllers to fix the output voltage of the circuit and apply this voltage to the inverter block by using a PV panel consists of a Maximum Power Point Tracking (MPPT) system, and by sampling from the output voltage of the proposed converter.

This block generates an AC signal and, after passing through a filter, it can supply the energy of a grid. For modeling and real-time application purposes, $200 \mathrm{Wp}$ and $24 \mathrm{~V}$ solar panels are used, which are located in Bursa Technical University, Electrical and Electronics Engineering Smart Grid Applications Laboratory.

Table I shows the technical specifications of the PV panels used in the developed system. The short circuit current and the open-circuit voltage are shown as (SC) and (OC) symbols. MPV and MPC are showing the maximum power voltage and currents for the panel, respectively. Also, the temperature coefficient is defined as $\beta$. 


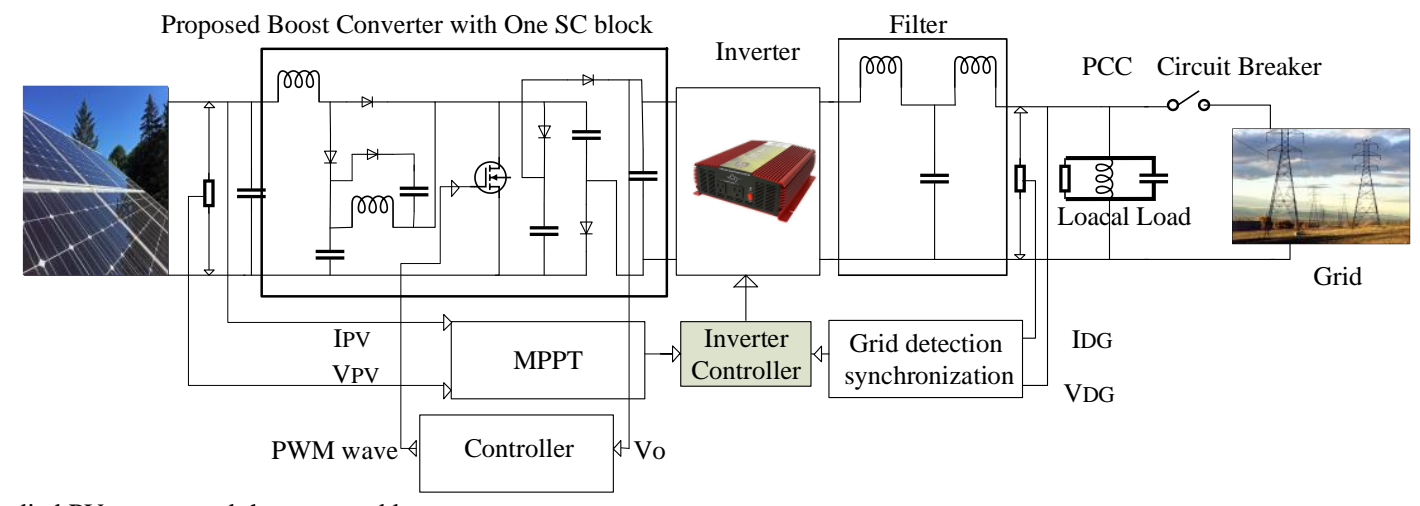

Fig. 1. The studied PV system and the proposed boost converter.

TABLE I. PV PANEL SPECIFICATIONS.

\begin{tabular}{|c|c|c|c|}
\hline Maximum power & $200 \mathrm{~W}$ & SC current (Isc) & $5.79 \mathrm{~A}$ \\
\hline MPV & $37.39 \mathrm{~V}$ & OC voltage (Voc) & $45.5 \mathrm{~V}$ \\
\hline MPC & $5.33 \mathrm{~A}$ & Number of cells & 72 \\
\hline \multicolumn{4}{|c|}{$\beta=-0.33$} \\
\hline
\end{tabular}

The proposed boost converter is shown in Fig. 2. A preamplifier unit is used in the converter design, and it is connected between the MOSFET and the input inductor. This new structure provides a high voltage gain in the converter system. The second voltage gain is provided with a switched capacitor block connecting after the MOSFET, and before the load\&output of the capacitor. This unit increases the voltage gain by two times, and it operates as a multiplier block. Fig. 2(a) shows this operation condition.

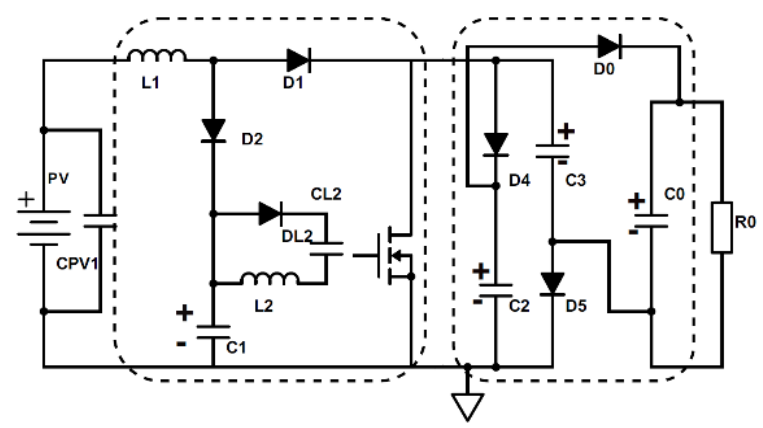

(a)

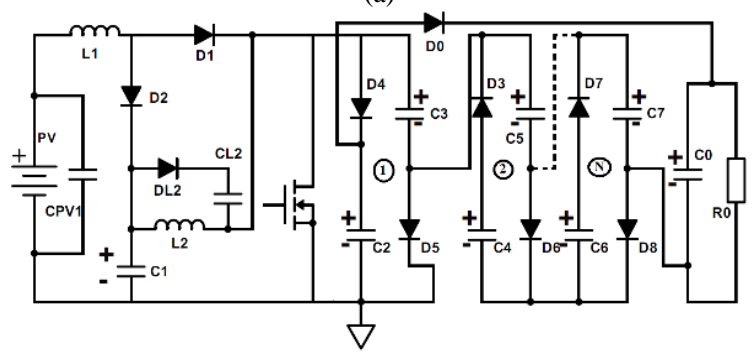

(b)

Fig. 2. The proposed converter with (a) one SC block and (b) extended blocks.

The $\mathrm{C}_{\mathrm{PV} 1}$ is a snubber capacitor to reduce the voltage oscillation that is produced by the PV panel (Fig. 2) [11]. The switched capacitor (SC) blocks can be connected in series to provide a high voltage gain in the proposed structure. A charge-discharge connection for inductor $\mathrm{L}_{2}$ is a significant design in the developed boost converter, and it makes a connection in parallel between capacitor $\mathrm{C}_{\mathrm{L} 2}$ and inductor to provide the charging process. The discharge process is also achieved by a serial connection of these two components. The same connection is extended to $\mathrm{L}_{1}$. Fig. 2(b) shows the proposed structure with more SC blocks.

\section{PERFORMANCE ANALYSIS OF CONVERTER-OPERATING MODES}

\section{A. Small Signal Analysis of the Proposed Converter}

An extended analysis should be considered for both the preamplifier layer and the $\mathrm{SC}$ block separately. $\mathrm{V}_{\mathrm{o} 1}$ is selected as the voltage of the drain pin of the switch to simplify the analysis and determinations. The MOSFET power switch is in the preamplifier block.

Thus, steady-state analysis and determinations are considered for this block. The MOSFET power switch is operated in $\mathrm{ON}$ and $\mathrm{OFF}$ modes by controlling pulses in gate-source pins, thus $\left[0, \mathrm{t}_{1}\right]$ and $\left[\mathrm{t}_{1}, \mathrm{~T}\right]$, time intervals are determined to analyze the structure. The power switch is ON mode for $\left[0, t_{1}\right]$ interval, and it is a short circuit in the converter. The zero voltage is received in gate-source pins of the power switch for $\left[\mathrm{t}_{1}, \mathrm{~T}\right]$ interval, so the MOSFET is disconnected and will be an open circuit (OFF mode).

Figure 3 indicates the conditions of the $\mathrm{ON}$ and $\mathrm{OFF}$ modes in the proposed converter. In this section, $\mathrm{ON}$ and OFF modes are analyzed.

Mode 1: Figure 3(a) shows magnetizing $\mathrm{L}_{1}$ and $\mathrm{L}_{2}$ for $[0$, $\mathrm{t}_{1}$ ] time interval. The input voltage provides this condition, and it is through the power switch for $\mathrm{L}_{1}$ inductor and diode $D_{1}$, and from switch and $C_{1}$ for the second inductor $L_{2} . D_{2}$ is in OFF mode in this condition, and the inductor currents increase in the ON state based on this status. Figure 4 shows different situations of all components for both time intervals to show the better explanation of the operating modes.

The $\mathrm{C}_{1}$ capacitor voltage value is discharging on $\mathrm{L}_{2}$ through the MOSFET and decreases. The voltage of the $\mathrm{C}_{2}$ discharges on the load through the $\mathrm{D}_{0}$ diode. In Mode 1 , the voltage of the output capacitor discharges on the output load. The current of diode $\mathrm{D}_{1}$ will increase because it is in conducting condition. Besides, the current of the diode $\mathrm{D}_{2}$ is zero.

Figure 5 illustrates the proposed structure with only the preamplifier part that can show the voltage on drain-source pins of the power switch is considered equal with $\mathrm{V}_{\mathrm{o}}$.

In this part, the steady space calculations are done for $\mathrm{ON}$ state.

The $\mathrm{L}_{1}$ and $\mathrm{L}_{2}$ inductors show the current waveforms, and $\mathrm{C}_{1}$ and $\mathrm{C}_{\mathrm{o}}\left(\mathrm{V}_{\mathrm{o} 1}\right)$ capacitors indicate the voltage waveforms 
according to the investigated conditions.

The steady-state condition of Mode 1 can be gained as the equations of a matrix below, respectively:

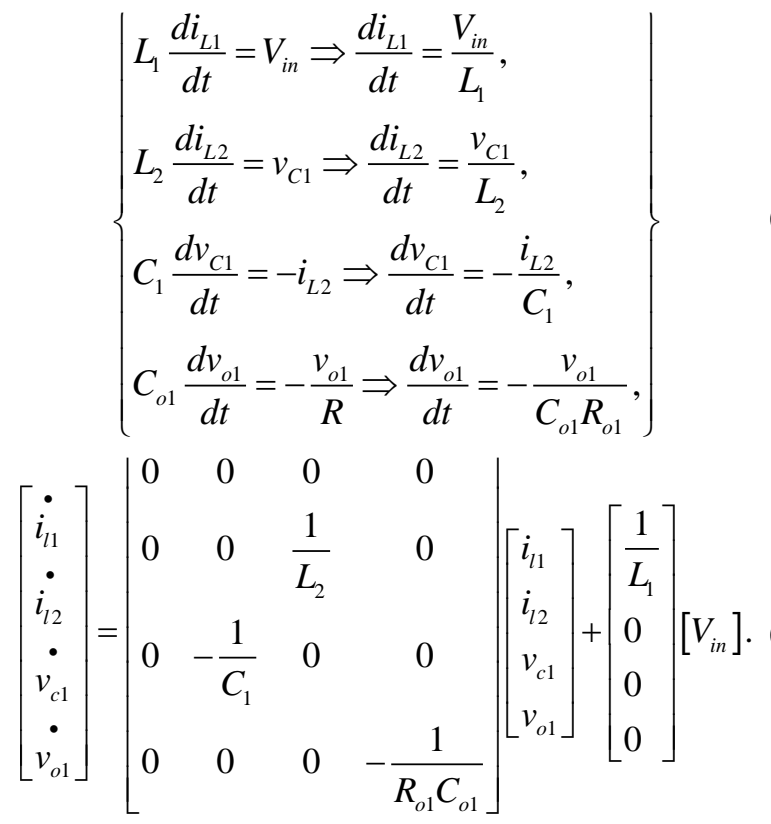

Mode 2: When the MOSFET is in OFF mode, the

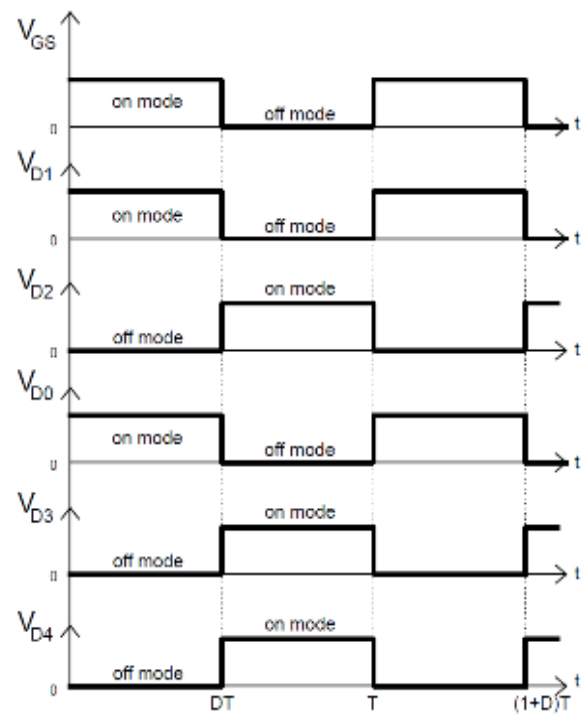

(a)

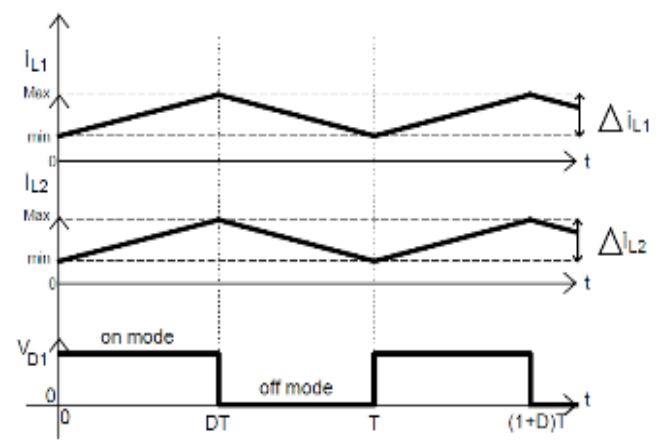

(c) condition of the circuit is shown in Fig. 3(b).

$\mathrm{L}_{1}$ is demagnetizing on capacitor $\mathrm{C}_{1}$ through $\mathrm{D}_{2}$, and $\mathrm{D}_{1}$ is in off mode in this time interval.

$\mathrm{L}_{2}$ is also demagnetizing through the $\mathrm{D}_{4}$ and $\mathrm{D}_{5}$ diodes on $\mathrm{C}_{2}$, and $\mathrm{C}_{3}$ capacitors.

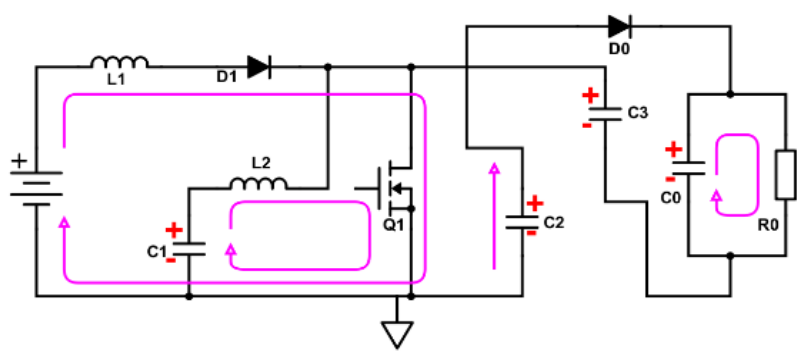

(a)

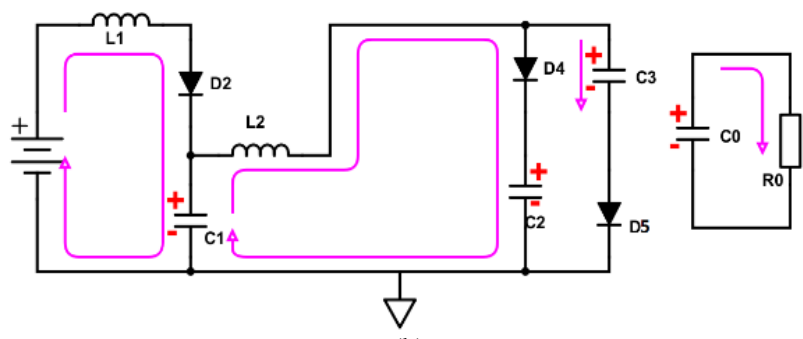

(b)

Fig. 3. State of the proposed structure (a) when the MOSFET is ON, and (b) when the MOSFET is OFF.

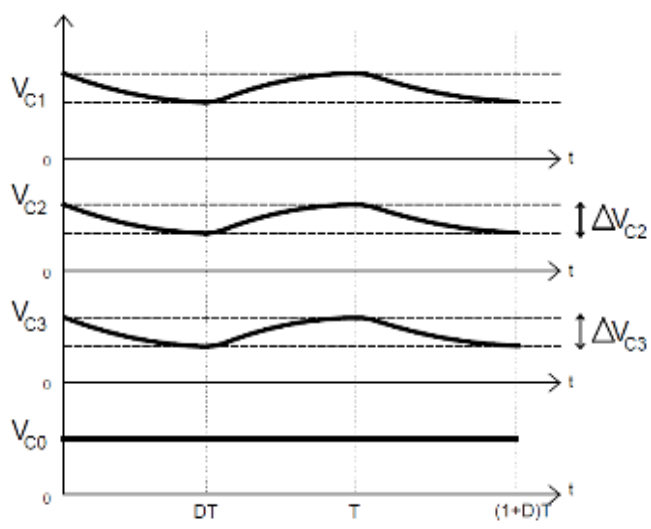

(b)

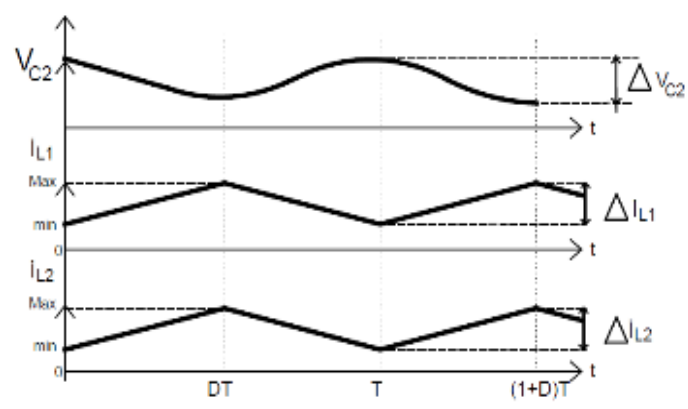

(d)

Fig. 4. The operation modes of the developed converter. 


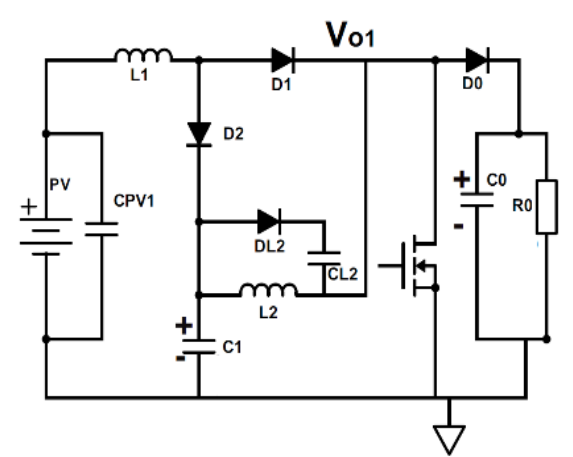

Fig. 5. The proposed structure with considering only the preamplifier part.

Figure 4 shows this condition. The voltages of $\mathrm{C}_{1}$ and $\mathrm{C}_{2}$ capacitors will increase through $\mathrm{L}_{1}$ and $\mathrm{L}_{2}$ inductors in this mode.

We can write current equations in this mode for inductors $\mathrm{L}_{1}$ and $\mathrm{L}_{2}$ and voltage equations for capacitors $\mathrm{C}_{1}$ and $\mathrm{C}_{0}$, and the steady space equations as (3) and (4):

$\left\{\begin{array}{l}L_{1} \frac{d i_{L 1}}{d t}=\left(V_{i n}-v_{C 1}\right)(1-d) \Rightarrow \frac{d i_{L 1}}{d t}=\frac{V_{i n}-v_{C 1}}{L_{1}}(1-d), \\ L_{2} \frac{d i_{L 2}}{d t}=\left(v_{C 1}-v_{o 1}\right)(1-d) \Rightarrow \frac{d i_{L 2}}{d t}=\frac{v_{C 1}-v_{o 1}}{L_{2}}(1-d), \\ C_{1} \frac{d v_{C 1}}{d t}=\left(i_{L 1}-i_{L 2}\right)(1-d) \Rightarrow \frac{d v_{C 1}}{d t}=\frac{i_{L 1}-i_{L 2}}{C_{1}}(1-d), \\ C_{o 1} \frac{d v_{o 1}}{d t}=\left(i_{L 2}-\frac{v_{o 1}}{R}\right)(1-d) \Rightarrow \frac{d v_{o 1}}{d t}=\frac{i_{L 2}-\frac{v_{o 1}}{R}}{C_{2}}(1-d),\end{array}\right\}$

where $d$ is the duty cycle applied to drive the MOSFET.

$$
\left.\left[\begin{array}{c}
\dot{i_{l 1}} \\
\dot{i_{l 2}} \\
\dot{v_{c 1}} \\
\dot{v_{o 1}}
\end{array}\right]=\left[\begin{array}{cccc}
0 & 0 & -\frac{1}{L_{1}} & 0 \\
0 & 0 & \frac{1}{L_{2}} & -\frac{1}{L_{2}} \\
\frac{1}{C_{1}} & -\frac{1}{C_{1}} & 0 & 0 \\
0 & \frac{1}{C_{2}} & 0 & -\frac{1}{R_{o 1} C_{o 1}}
\end{array}\right] \mid \begin{array}{l}
i_{l 1} \\
i_{l 2} \\
v_{c 1} \\
v_{o 1}
\end{array}\right]+\left[\begin{array}{l}
\frac{1}{L_{1}} \\
0 \\
0 \\
0
\end{array}\right]\left[V_{i n}\right] .
$$

The Pulse Width Modulation (PWM) adjusts the ON and OFF states in the developed structure.

Waveforms of capacitors $C_{1}$ and $C_{2}$, and the steady-state matrix of the structure will propose a bunch of equations that are presented as (5) and (6):

$$
\left\{\begin{array}{l}
\frac{d i_{L 1}}{d t}=-\frac{(1-d)}{L_{1}} v_{C 1}+\frac{1}{L_{1}} V_{i n} \\
\frac{d i_{L 2}}{d t}=\frac{1}{L_{2}} v_{C 1}-\frac{(1-d)}{L_{2}} v_{o 1} \\
\frac{d v_{C 1}}{d t}=\frac{(1-d)}{C_{1}} i_{L 1}-\frac{1}{C_{1}} i_{L 2} \\
\frac{d v_{o 1}}{d t}=\frac{(1-d)}{C_{2}} i_{L 2}-\frac{1}{R_{o 1} C_{o 1}} v_{o 1}
\end{array}\right\}
$$

$$
\left[\begin{array}{c}
\dot{i_{l 1}} \\
\dot{i_{l 2}} \\
\dot{v_{c 1}} \\
\dot{v_{o 1}}
\end{array}\right]=\left[\begin{array}{cccc}
0 & 0 & -\frac{1-d}{L_{1}} & 0 \\
0 & 0 & \frac{1}{L_{2}} & -\frac{1-d}{L_{2}} \\
\frac{1-d}{C_{1}} & -\frac{1}{C_{1}} & 0 & 0 \\
0 & \frac{1-d}{C_{o 1}} & 0 & -\frac{1}{R_{o 1} C_{o 1}}
\end{array}\right]\left[\begin{array}{l}
i_{l 1} \\
i_{l 2} \\
v_{c 1} \\
v_{o 1}
\end{array}\right]+\left[\begin{array}{l}
\frac{1}{L_{1}} \\
0 \\
0 \\
0
\end{array}\right]\left[V_{i n}\right] .(6)
$$

The voltage, charge, and discharge conditions of the capacitors are shown in Fig. 4(b), changing according to the MOSFET switching states. When the capacitor block $\left(\mathrm{C}_{2}\right.$ and $C_{3}$ ) is switched, the same response is obtained, and it is indicated in Fig. 4(b). These two capacitors will charge and discharge simultaneously, as it was predictable from Fig. 3(a) and Fig. 3(b).

Figure 4 shows all of the conditions of the components, covering waveforms of capacitor voltages and inductor currents. Figure 4(a) also shows the power semiconductor components' conditions of topology. $\mathrm{D}_{1} \& \mathrm{D}_{0}$ diodes are in $\mathrm{ON}$ mode, and $\mathrm{D}_{2} \& \mathrm{D}_{3}$ diodes are in OFF mode when the MOSFET is ON. If the MOSFET is OFF, then $\mathrm{D}_{1} \& \mathrm{D}_{0}$ diodes are in $\mathrm{OFF}$ mode, and $\mathrm{D}_{2} \& \mathrm{D}_{3}$ diodes are in a disconnected mode, respectively.

Both inductors are magnetizing for the time interval $\left[0, \mathrm{t}_{1}\right]$ when the MOSFET is in ON state. The inductors are demagnetizing, and the inductor currents reduce for OFF interval. Figure 4(c) shows these conditions.

Figure 4(d) shows the relation between the switched capacitors' voltages and inductors' currents. The voltage gain calculation and the operation modes of the SC block are evaluated in this part. The SC block located between the MOSFET and load in the converter to double up the drainsource (first block) voltage.

The new design of the SC block consists of two capacitors and two diodes, and it is indicated in Fig. 2(a). The connection of the capacitors and diodes should be changed if the SC block is desired to be extended. In this case, it is required to be connected in forwarding bias $\left(\mathrm{D}_{4-}\right.$ $\mathrm{D}_{5}-\mathrm{C}_{2}-\mathrm{C}_{3}$ ), and another block should be perched in reversed bias like $\left(\mathrm{D}_{3}-\mathrm{D}_{6}-\mathrm{C}_{4}-\mathrm{C}_{5}\right)$ and $\left(\mathrm{D}_{7}-\mathrm{D}_{8}-\mathrm{C}_{6}-\mathrm{C}_{7}\right)$.

The inductor voltages and reverse and forward biased capacitor voltages by considering Fig. 2(a), the voltage equations are determined as

$$
\begin{gathered}
V_{P V-\text { Panel }} D T_{s}=\left(V_{C_{2} \text { or } C_{3}}-V_{P V-\text { Panel }}\right)(1-D) T_{s}= \\
=\left(V_{C_{4} \text { or } C_{5}}-V_{P V-\text { Panel }}\right)(1-D) T_{s},
\end{gathered}
$$

where $T_{s}$ is the period of the switching frequency, and the $\mathrm{V}_{\mathrm{PV} \text {-Panel }}$ is the voltage value presented by the panel.

$$
V_{P V-\text { Panel }} D T_{s}=V_{C_{2} \text { orC }}(1-D) T_{s}=V_{C_{4} \text { orC }}(1-D) T_{s} .
$$

The SC block increase the voltage and the voltage of the Forward Biased Capacitor (FBC) can be determined as

$$
V_{F B C}=\left(\frac{V_{P V-\text { panel }}}{1-D}\right)
$$


The output voltage $V_{o}$ and the DC voltage gain $G$ can be determined in (10) and (11) for an N-stage SC block:

$$
\begin{gathered}
G=\frac{V_{o}}{V_{P V-\text { panel }}}=\left(\frac{N}{1-D}\right), \\
V_{o}=N \times V_{o 1} \Rightarrow G=\frac{V_{o}}{V_{\text {in }}}=\frac{V_{o}}{V_{o 1}} \times \frac{V_{o 1}}{V_{\text {in }}} \simeq \frac{N}{(1-D)^{2}} .
\end{gathered}
$$

\section{B. Assessing the Developed Converter's Voltage Gain}

The determined model of the proposed boost converter is indicated in Fig. 6(a) by considering the inductors' internal resistances.

By a simple simulation, it will become clear that, for a boost converter, the main source of losses belongs to the power diodes and MOSFETs.

Thus, the final DC gain of the proposed boost converter structure will not be less than the determined DC gain equation by considering the similar voltage drops on inductors, capacitors, and other power components. The internal resistance is considered for inductors, and a voltage drop indicated as a $\mathrm{V}_{\mathrm{d}}$ value is also assumed for all power diodes and switches to provide the final DC gain.

The gain value is presented by (14) in this study, and (12) and (13) will help to understand the voltage gain calculation procedure.

Also, (15) presents the proposed converter's DC voltage gain without consideration of the losses. Figure 6(a) shows this drop value for defined components.

The determination of the voltage gains changes into two different modes according to the charge and discharge conditions of the inductors.

The power switch is considered for ON and OFF modes to evaluate the voltage value through the inductors.

Figure 6(b) and Fig. 6(c) show the components with the internal resistance in $\mathrm{ON}$ and $\mathrm{OFF}$ modes of the power switch, respectively. When the switch is in ON mode, $\mathrm{R}_{\mathrm{ON} 1}$ is the resistance values of the power switch in drain-source pins when the switch is in ON mode.

\section{1) State 1}

The voltage of the $\mathrm{L}_{1}$ inductor, when the power MOSFET is in the ON and OFF operation modes: The voltage of the $\mathrm{L}_{1}$ inductor, when the power switch is $\mathrm{ON}$ mode will be determined as below

$$
\begin{gathered}
\left(V_{i n}-3 V_{d}\right) D+\left(V_{i n}-V_{C 1}-2 V_{d}\right)(1-D)=0 \Rightarrow \\
\Rightarrow V_{c 1}=V_{i n}\left(\frac{1}{1-D}\right)-V_{d}\left(\frac{2+D}{1-D}\right) .
\end{gathered}
$$

The switch ON time interval is defined as $\mathrm{D}$, and the switch OFF time interval is defined as (1-D) in the above equation.

\section{2) State 2}

The voltage of the $\mathrm{L}_{2}$ inductor, when the power MOSFET is in the ON and OFF operation modes: The voltage of the $\mathrm{L}_{2}$ inductor, when the power switch is $\mathrm{ON}$, and OFF modes will be determined as (13)

$$
\begin{gathered}
\left(V_{c 1}-2 V_{d}\right) D+\left(V_{c 1}-V_{o}-2 V_{d}\right)(1-D)=0 \Rightarrow \\
\Rightarrow V_{o}=V_{c 1}\left(\frac{1}{1-D}\right)-V_{d}\left(\frac{2}{1-D}\right) .
\end{gathered}
$$

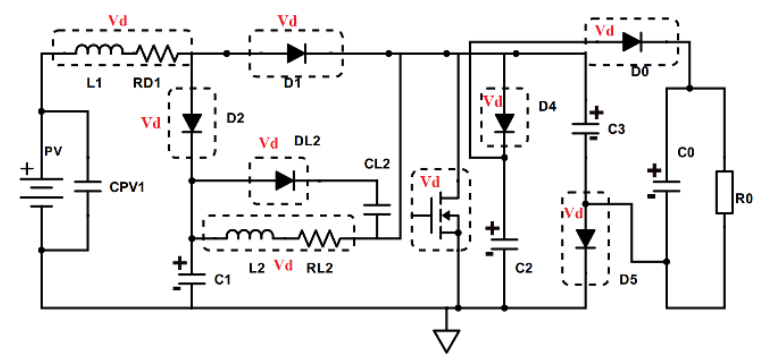

(a)

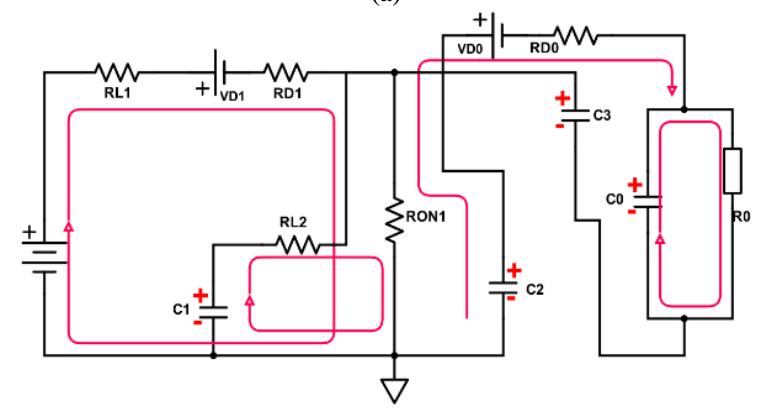

(b)

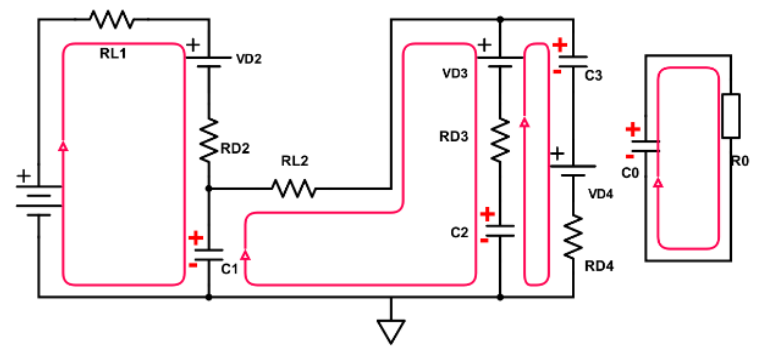

(c)

Fig. 6. The voltage drops and internal resistances effects developing an equivalent circuit of the proposed converter.

The voltage gain of the proposed structure can be determined by replacing (12) into (13)

$$
\begin{gathered}
V_{o 1}=\frac{V_{i n}\left(\frac{1}{1-D}\right)-V_{d}\left(\frac{2+D}{1-D}\right)}{1-D}-2 V_{d}\left(\frac{1}{1-D}\right) \Rightarrow \\
\Rightarrow V_{o}=\frac{V_{i n}-V_{d}(4-D)}{(1-D)^{2}}-2 V_{d}\left(\frac{1}{1-D}\right) \Rightarrow \\
\Rightarrow V_{o}=V_{i n} \frac{1}{(1-D)^{2}}-V_{d} \frac{4-D}{(1-D)^{2}} .
\end{gathered}
$$

In equation (14), the terms $\mathrm{V}_{\mathrm{d}}(4-\mathrm{D}) /(1-\mathrm{D})^{2}$ can be ignored by considering the small values of $\mathrm{V}_{\mathrm{d}}$ and (4-D) components compared with the denominator.

The switched-capacitor block in the projected circuit increases the voltage DC gain by two times. Thus, the total voltage gain of the converter can be determined with (15)

$$
V_{o}=2 \times V_{o 1} \Rightarrow G=\frac{V_{o}}{V_{i n}}=\frac{V_{o}}{V_{o 1}} \times \frac{V_{o 1}}{V_{i n}} \simeq \frac{2}{(1-D)^{2}} .
$$

\section{Components' Values Calculations}

One of the most important issues is the selection of the 
proper components in a power circuit since the main resources of the power losses are the internal resistance of the inductors and power components like diodes and switches in ON and OFF states of the circuit.

These losses can be categorized in dynamic losses since different levels of the current flow through these elements. The largest power losses can be seen on the power MOSFET when it works in ON state on drain-source pins resistance, $\mathrm{R}_{\mathrm{ON}}$. The IXTH 40N30 type of the MOSFETs is selected where it has a $0.085 \Omega$ as $\mathrm{R}_{\mathrm{ON}}$.

The DESP15-06A type of diodes are selected by $\mathrm{V}_{\mathrm{D}}=1.41 \mathrm{~V}$ for the forward bias voltage and known as the fast recovery diode.

The main criteria are the current fluctuations values in inductors selection. Normally 20 till $40 \%$ of current ripples can be evaluated as the proper ripple value for this current. Since the PV array by JIYANGYIN HR-24V/200W specifications is used for the laboratory prototype, by considering the $48 \mathrm{VDC}$ and $400 \mathrm{VDC}$ for the input and output voltages of the power converter respectively, and $0.5 \mathrm{~A}$ as the maximum output current, the current ripple for the first inductor can be obtained by (16)

$$
\Delta i_{L 1}=0.3 \times I_{\text {OUT }(\text { Max })} \times \frac{V_{\text {OUT }(\text { Max })}}{V_{I N(\min )}}=1.25 \mathrm{~A} .
$$

Since the generated voltage by the input PV panel changes between 24 till 48 VDC based on temperature and irradiance, for $100 \mathrm{kHz}$ as the switching frequency, the value of the first inductor can be calculated

$$
L_{1}=\frac{V_{I N(\operatorname{Max})}\left(V_{\text {OUT }(\text { Max })}-V_{I N(\operatorname{Max})}\right)}{\Delta i_{L 1} f_{s} V_{\text {OUT }(\text { Max })}} \simeq 337 \mu \mathrm{H} .
$$

Calculations should be considered for the worst working conditions. So by having the same current for the second inductor $\mathrm{L}_{2}$, by the same value of the inductor, around 1.25 , A will be followed.

By the theoretical calculations, by having 200 VDC for the point $\mathrm{V}_{\mathrm{o}}$, the voltage value on the $\mathrm{C}_{1}$ can be obtained as 100 VDC. For the fast charge and discharge of the capacitance, it should be selected smaller than inductors $\mathrm{L}_{1}$ and $\mathrm{L}_{2}$. So it can be selected equal to $5 \mu \mathrm{F}$ The value of the output capacitor can found by

$$
C_{\text {OUT }}=\frac{D \times I_{\text {OUT (Max })}}{f_{s} \Delta V_{\text {OUT }}}=\frac{52 \times 0.5}{100 K \times 1}=260 \mu \mathrm{F} .
$$

If the ripple of the output voltage is considered as $1 \%$, for a $200 \mathrm{~W}$ and $400 \mathrm{VDC}$ system, the duty cycle is changed around $0.52(52 \%)$.

The output capacitor is selected around $260 \mu \mathrm{F}$. In the ON working station for the switch, the maximum current of IOUT will flow through capacitors $\mathrm{C}_{2}$ and $\mathrm{C}_{3}$ because of the serial path creation between the input PV array and the output load. These capacitors values by $1 \%$ of fluctuation can be calculated by

$$
C_{2}=C_{3}=\frac{I_{\text {OUT }(\text { Max })}}{f_{s} \Delta V_{\text {OUT }}}=\frac{0.5}{100 K \times 1}=5 \mu \mathrm{F} .
$$

Also, the amount of $\mathrm{C}_{\mathrm{L} 2}$ is selected equal to $20 \mu \mathrm{F}$ and is significant compared with $\mathrm{L}_{2}$.

Based on calculations, Table II presents the components' values for experimental and simulation analysis of the

\begin{tabular}{|c|c|c|c|}
\hline \multicolumn{2}{|c|}{ Simulation } & \multicolumn{2}{|c|}{ Experimental } \\
\hline $\begin{array}{l}\mathrm{L}_{1} \text { and } \mathrm{L}_{2} \\
\text { inductors }\end{array}$ & $330 \mu \mathrm{H}$ & $\begin{array}{l}\mathrm{L}_{1} \text { and } \mathrm{L}_{2} \\
\text { inductors }\end{array}$ & $330 \mu \mathrm{H}$ \\
\hline $\begin{array}{l}\mathrm{C}_{1}, \mathrm{C}_{2}, \mathrm{C}_{3} \\
\text { capacitors }\end{array}$ & $5 \mu \mathrm{F}$ & $\begin{array}{l}\mathrm{C}_{1}, \mathrm{C}_{2}, \mathrm{C}_{3} \\
\text { capacitors }\end{array}$ & $5.6 \mu \mathrm{F}$ \\
\hline Co capacitor & $260 \mu \mathrm{F}$ & Co capacitor & $270 \mu \mathrm{F}$ \\
\hline Input voltage & $48 \mathrm{~V}$ & Input voltage & $48 \mathrm{VDC}$ \\
\hline Output voltage & $380 \mathrm{~V}$ & Output voltage & $380 \mathrm{VDC}$ \\
\hline $\begin{array}{l}\text { Switching } \\
\text { frequency }\end{array}$ & $100 \mathrm{KHz}$ & $\begin{array}{l}\text { Switching } \\
\text { frequency }\end{array}$ & $100 \mathrm{KHz}$ \\
\hline $\begin{array}{c}\text { Power } \\
\text { MOSFET }\end{array}$ & $\begin{array}{l}\text { Matlab model } \\
\text { (IXTQ460P2) }\end{array}$ & MOSFET & IXTQ460P2 \\
\hline Power Diodes & $\begin{array}{l}\text { Matllab model } \\
\text { (DESP15-06A) }\end{array}$ & Power Diodes & $\begin{array}{c}\text { DESP15- } \\
\text { 06A }\end{array}$ \\
\hline Output power & $0-500 \mathrm{~W}$ & Output power & $200 \mathrm{~W}$ \\
\hline
\end{tabular}
projected converter. For the experimental prototype, the nearest standard values are selected.

TABLE II. COMPONENTS' VALUES.

\section{RESULTS AND DISCUSSION}

\section{A. Performance Analysis for the Projected Circuit}

Four different configuration of the Boost converter including the Conventional (CB), Cascaded Conventional (Cas-B) [2], the Proposed Boost with the Pre-Amplifier (PA$\mathrm{PB})$ and (PA-PB) with the Switched -Capacitor (PA-PB and $\mathrm{SC}$ ) blocks selected and tested by the MATLAB/SIMULINK for voltage gain and efficiency assessments.

The facts presented in section III have been considered for elements selection. Under different duty cycles of the switch, $48 \mathrm{VDC}$ and 100 till $2 \mathrm{k} \Omega$ for PV-side voltage and load values have been considered.

Figure 7 illustrates that the gain is increasing when the duty cycle is greater.

The proposed structure with SC block generates the greatest DC gain, and for $50 \%$ of duty cycle, around $375 \mathrm{~V}$ is generated by this converter by $48 \mathrm{VDC}$ in the input side, while 384 VDC for the ideal working condition is expected. The current waveforms for the input inductor are presented in Fig. 8(a) under the same input voltage and duty cycle. For this purpose, all these topologies are considered to generate different voltage gains according to their capabilities.

For example, where the conventional boost converter generates the $96 \mathrm{VDC}$ in its output, the proposed converter with the SC block produces around 375 VDC, as mentioned in this section.

The highest ripples values are reported for the $\mathrm{CB}$ for the same rated power in all converters with the minimum current variation of $1.2 \mathrm{~A}$ peak to peak since $0.3 \mathrm{~A}$ is reported for the proposed structure by the same 96 VDC as output voltage and 1.2 A for the 375 VDC. Figure 8(b) shows the second inductor's current waveforms for Cas-B, PA-PB and PA-PB, and SC topologies.

This figure illustrates that the current oscillation for the $\mathrm{L}_{2}$ inductor for both cascade and PA-PB structures approximately are the same. 
Also, as can be followed, for light loads, the projected converter can guarantee to act in Continuous Current Mode (CCM), where other structures can enter to Discontinuous Current Mode (DCM) because, as the figure shows, the current becomes zero for a while for these topologies.

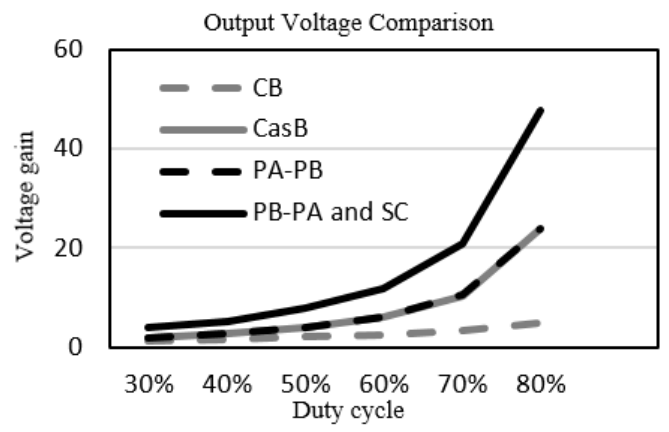

Fig. 7. The DC gain curves for the (CB), (Cas-B), (PA-PB) and (PA-PB and SC) blocks.

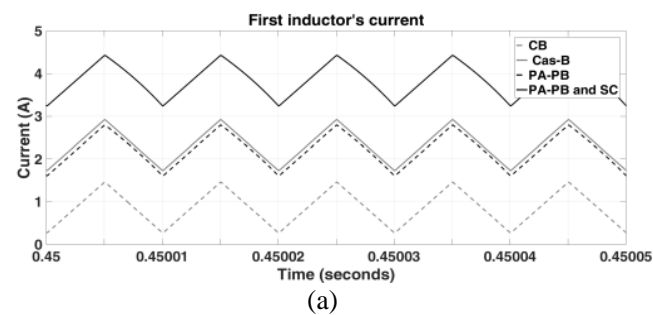

(a)

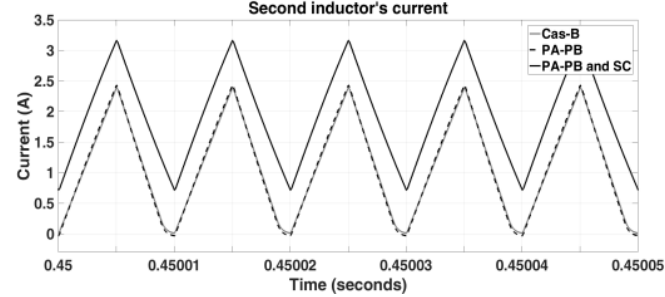

(b)

Fig. 8. The input currents for the $\mathrm{CB}, \mathrm{CasB}, \mathrm{PA}-\mathrm{PB}$, and PA-PB and SC: a) First and b) the Second inductor.

Efficiency assessment has been done through Fig. 9 for these converters in a large band of the output powers from 25 to $500 \mathrm{~W}$.

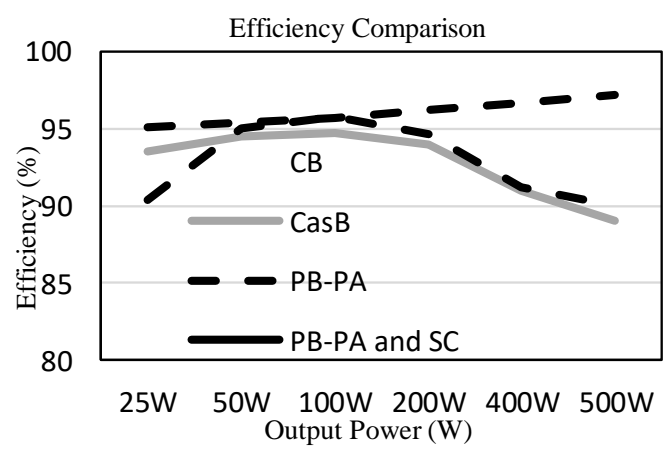

Fig. 9. Efficiency assessment for the CB, CasB, PA-PB and PA-PB and SC.

The (PA-PB) converter presents the best results for low and high power values. The efficiency of the (PA-PB and $\mathrm{SC}$ ) is considerable for the 50 till $200 \mathrm{~W}$ range of the output powers is considerable in comparison with all other structures.

For this purpose, $48 \mathrm{VDC}$ as the input voltage is considered for all converters, and by changing the output load from $100 \Omega$ till $2 \mathrm{~K} \Omega$, so the different values of the output currents. As a result, different values of the output powers are gained.

According to the results in Fig. 9, by considering the more SC blocks, since a larger number of the components are applied, a decrement for the efficiency is predictable compared with CB or Cas-B presented in [6]. Since the limited value of the power is generated by Renewable Energy Sources, the high gain boost converters have the majority of the importance to be applied.

So, a trade-off should be done between efficiency and high gain applications when a boost converter is a subject.

\section{B. Experimental Results for the Projected Circuit}

A prototype of the proposed PA-PB and SC converter implemented in the laboratory. N-channel IXTQ460P2 MOSFET and DESP15-06A diode are selected for power semiconductors. $\mathrm{C}_{1}, \mathrm{C}_{2}, \mathrm{C}_{3}$, and $\mathrm{C}_{0}$ are selected as $5.6 \mu \mathrm{F}$, $5.6 \mu \mathrm{F}, 5.6 \mu \mathrm{F}$, and $270 \mu \mathrm{F}$, respectively. $330 \mu \mathrm{H}$ inductors are selected for $\mathrm{L}_{1}$ and $\mathrm{L}_{2}$.

As mentioned in Sections II and III, two serial HR-200W$24 \mathrm{~V}$ solar arrays with $48 \mathrm{VDC}$ input voltage in 25 degrees centigrade under the full load working situation and 380 VDC output voltage, $100 \mathrm{kHz}$ switching frequency and $200 \mathrm{~W}$ output power, and with a full load of $100 \Omega$ till $2 \mathrm{~K} \Omega$ is considered for the laboratory tests.

Figure 10 illustrates the experimental results for the proposed structure. In Figure 10(a), current waveforms of the circuit are presented.

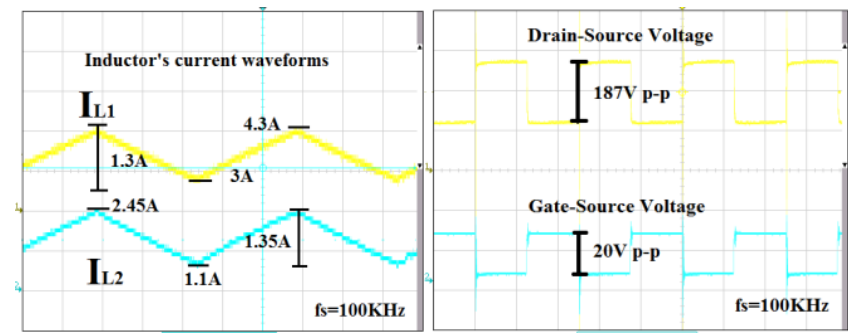

(a)

(b)

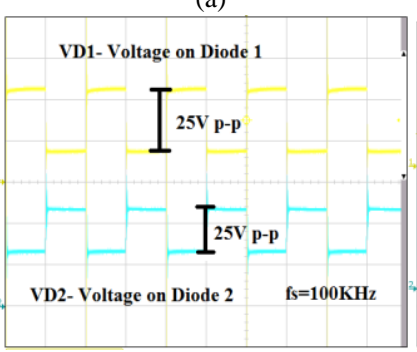

(c)

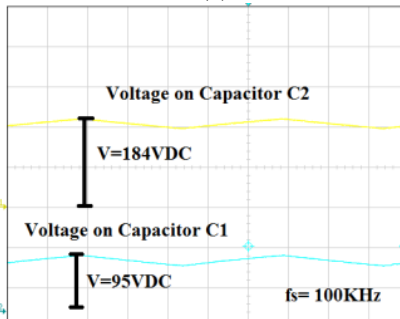

(e)

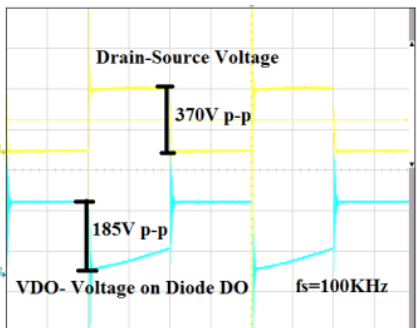

(d)

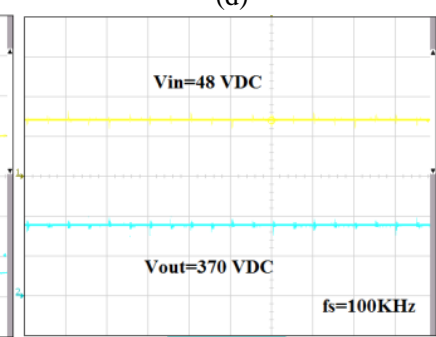

(f)
Fig. 10. a) Current waveforms of the inductors; b) Voltages on drainsource and gate-source pins; c) Voltages on diodes $\mathrm{D}_{1}$ and $\mathrm{D}_{2}$; d) Voltages on drain-source and output diode DO; e) Voltages on capacitors $\mathrm{C}_{1}$ and $\mathrm{C}_{2}$; (f) Output and input voltages.

As can be predicted, the oscillation of the current for input 
inductor is higher, and the working condition of the designed converter guarantees to act in CCM. Figure 10(b) shows the voltages on drain-source and gate-source pins of the power MOSFET, and it illustrates that when the switch receives a signal in the gate pin, it goes to conduct and work as a short circuit component.

Also, by considering the 380 VDC as the output voltage, drain-source pins can produce the half of this voltage] around $140 \mathrm{~V}$. Figure 10 (c) shows the voltage on diodes $\mathrm{D}_{1}$ and $\mathrm{D}_{2}$ to test the reliability of the circuit and, as can be seen, it confirms the mathematical analysis of the proposed converter that presented in Fig. 5(a) correctly, and when one of these diodes is short circuit, another will be in an open circuit situation.

The drain-source and Diode $\mathrm{D}_{\mathrm{O}}$ voltages are presented in Fig. 10(d), and as we expected from Fig. 5(a) $D_{O}$ acts simultaneously with the gate-source voltage and asynchronous with the drain-source voltage. Figure 10(e) illustrates the voltages on capacitors $\mathrm{C}_{1}$ and $\mathrm{C}_{2}$.

The voltage on the Capacitor $\mathrm{C}_{1}$ presents the quarter and $\mathrm{C}_{2}$ half of the output voltage. Finally, Fig. 10(f) presents the input and output voltages.

\section{CONCLUSIONS}

A high gain DC-DC Boost converter, including a quadratic configuration in the input side and a switchedcapacitor (SC) circuit in the output side, is presented in this study. Compared with the classical Boost converters, higher reliability for the SC and stand-alone RESs based high gain Boost systems is reported for the 380 VDC of the output voltages for more efficient power transmission purposes. The introduced power converter includes three power diodes, two inductors and two capacitors in the quadratic side and one-two diodes and two capacitors for the SC block and only one power switch. Both ON and OFF states of the switch analyzed and the configuration of the converter under both working stations investigated to confirm the converter's entrusting with the standalone photovoltaic array operating at standard test situations.

The overall contribution of the study to the literature could be presented, respectively: a) A new DC-DC power Boost converter based on two separate sides including PA boosting and SC blocks is implemented for residential PV applications; b) The structure is that's the ability to add more SC blocks in order to decrease the voltage stress on the power switch and power diodes for higher voltage gains; c) The voltage gain of the proposed structure is $2 /(1-\mathrm{d})$ times greater than a conventional converter, since, in an $80 \%$ of duty cycle, the voltage gain is around 48 times in proposed converter in simulation and 50 times ideally, and in an $50 \%$ of duty cycle, 4.95 times in simulation and 5 times ideally in the conventional converter; d) Using SC block is the reduction of stress on the switch components. The general structures of the proposed converter permits applying more SC layers, which obtain not only higher DC voltage gain, but also fewer stresses on power MOSFET; e) The converter topology that allows obtaining the same output voltage at a lower duty cycle in comparison with conventional boost converter, which directly leads to a reduction in general current levels in the converter and a limitation of dynamic losses and increasing the efficiency; f) The developed converter is highly efficient and practical for residential PV applications.

\section{CONFLICTS OF INTEREST}

The authors declare that they have no conflicts of interest.

\section{REFERENCES}

[1] Z. U. Bayrak, G. Bayrak, M. T. Ozdemir, M. T. Gencoglu, and A. Cebeci, "A low-cost power management system design for residential hydrogen \& solar energy-based power plants," International Journal of Hydrogen Energy, vol. 41, pp. 12569-12581, 2016. DOI: 10.1016/j.ijhydene.2016.01.093.

[2] H. Feroura, F. Kerim, B. Talbi, A. Laib, and A. Belaout, "Finite-set model predictive direct power control of grid-connected current source inverter," Elektronika Ir Elektrotechnika, vol. 23, pp. 36-40, 2017. DOI: 10.5755/j01.eie.23.5.19240.

[3] J. S. Lee, H. W. Sim, J. Kim, and K. B. Lee, "Combination analysis and switching method of a cascaded $\mathrm{H}$-bridge multilevel inverter based on transformers with the different turns ratio for increasing the voltage level," IEEE Trans. Ind. Electron., vol. 65, no. 6, pp. 44544465, 2018. DOI: 10.1109/TIE.2017.2772139.

[4] J. S. Kim, J. M. Kwon, and B. H. Kwon, "High-efficiency two-stage three-level grid-connected photovoltaic inverter," IEEE Trans. Ind. Electron., vol. 65, pp. 2368-2377, 2018. DOI: 10.1109/TIE.2017.2740835.

[5] O. Ray and S. Mishra, "Constant-frequency shoot-through sine pulsewidth-modulation scheme for three-phase single-input-hybrid-output converter," IET Power Electron., vol. 9, pp. 1819-1827, 2016. DOI: 10.1049/iet-pel.2015.0731

[6] M. Sahoo and S. Keerthipati, "Fault-tolerant three-level boost inverter with reduced source and LC count," IET Power Electron., vol. 11, pp. 399-405, 2018. DOI: 10.1049/iet-pel.2017.0085.

[7] Z. Wang, J. Chai, and X. Sun, "Method to control flux balancing of high-frequency transformers in dual active bridge dc-dc converters," J. Eng., vol. 2018, pp. 1835-1843, 2018. DOI: 10.1049/joe.2018.8338.

[8] X. Hu and C. Gong, "A high voltage gain DC-DC converter integrating coupled-inductor and diode-capacitor techniques," IEEE Trans. Power Electron., vol. 29, pp. 789-800, 2014. DOI: 10.1109/TPEL.2013.2257870.

[9] P. C. Heris, Z. Saadatizadeh, E. Babaei, and M. Sabahi, "New high step-up two-input-single-output converter with low-voltage stresses on switches and zero input currents ripple," IET Power Electron., vol. 11, pp. 2241-2252, 2018. DOI: 10.1049/iet-pel.2018.5580.

[10] J. Yang, D. Yu, H. Cheng, X. Zan, and H. Wen, "Dual-coupled inductors based high step-up DC/DC converter without input electrolytic capacitor for PV application," IET Power Electron., vol. 10, pp. 646-656, 2017. DOI: 10.1049/iet-pel.2016.0536.

[11] D. Ghaderi, M. Çelebi, M. R. Minaz, and M. Tören, "Efficiency improvement for a DC-DC quadratic power boost converter by applying a switch turn-off lossless snubber structure based on zero voltage switching," Elektronika Ir Elektrotechnika, vol. 24, pp. 1522, 2018. DOI: 10.5755/j01.eie.24.3.20977. 